\title{
Somaclonal variations as a mean for obtaining regenerants with different growth rates in poplar (Populus $\times$ berolinensis Dipp.)
}

\author{
Kim Z. Gamburg*, Viktor K. Voinikov \\ Siberian Institute of Plant Physiology and Biochemistry, Siberian Branch of the Russian Academy of Sciences, Irkutsk, Russia; \\ *Corresponding Author: gamburg@sifibr.irk.ru
}

Received 7 March 2013; revised 9 April 2013; accepted 25 April 2013

Copyright (C) 2013 Kim Z. Gamburg, Viktor K. Voinikov. This is an open access article distributed under the Creative Commons Attribution License, which permits unrestricted use, distribution, and reproduction in any medium, provided the original work is properly cited.

\begin{abstract}
Adventive regenerants of Populus $\times$ berolinensis Dipp. were obtained on $1 / 2$ MS salts with sucrose, vitamins, BA, TDZ and NAA using stem, petiole and leaf explants. They differed from each other in plantlet dimensions. More than $\mathbf{5 0}$ clones were produced from initial regenerants by excision and rooting of apexes and lateral shoots. Differences in stem length and thickness were observed between 200 field plants produced from in vitro plantlets. Differences in stem length were conditioned mainly due to different number of internodes and not by internodes' lengths. Plants grown from cuttings excised from highest and smallest plants retained the abilities of mother plants to grow with different rates. It is concluded that somaclonal variability can be used for selection of fast growing poplar plants which are necessary for industrial plantations. These plants can be used for this purpose without the limitations existing for transgenic plants.
\end{abstract}

Keywords: Somaclonal Variations; Adventive Regenerants; Poplar; Populus x Berolinensis Dipp. Propagation in Vitro; Fast Growing Plants

\section{INTRODUCTION}

Different poplar species (Populus $s p$.) have great scientific and economic significance due to small genome size, fast growth, short rotation cycle and ability for vegetative propagation [2]. They are widely used for settlement's greening, creation of forest shelter belts and as a source of timber wood. A new application of poplar biomass as a source of biofuel is developed in last times
[2-5].

In order to meet the growing demands for wood biomass, industrial plantations are built up and more productive varieties of poplar are selected. Genetic transformation of poplar draws attention for growth fastening [6,7], decrease of lignin content [8-10], and increase of the resistance to pests [11]. This transformation is facilitated due to the fact that the genome of poplar is fully sequenced in recent time $[12,13]$ and now it is considered as a model for the study of molecular biology of woody plants [14]. However, a real practical use of transgenic poplars is hindered from the apprehension of unregulated carrying over their pollen and seeds and possibility for rise of transgenic plants in natural forests [15]. So, creation of industrial plantations of transgenic poplars is prohibited in Russia and in some other countries.

It is known that there is a probability for the appearance of genetic deviations from starting plant material used for induction of adventive regenerants in isolated tissue culture. It is named somaclonal variability and is considered as a mean for plant selection [16-18]. Mutants with increased resistance to herbicides of poplar, to diseases of larch, to heavy metals and other characteristics were obtained by this method [17]. Disadvantages of the somaclonal variability are 1) low frequency of desired variants; 2) most of deviations are undesired; 3) many deviations have epigenetic character [17]. However, there are no strict limitations for practical use of new plant varieties originated from somaclonal variability.

There are many publications which describes the obtaining tissue cultures, clonal micropropagation and regenerants of poplar [19-24]. Protocols for induction of regenerants are described also in many articles devoted to genetic transformation of poplars. Different poplar species and varieties, medium compositions, including plant 
growth regulators and their proportions have been applied in these works. Main conclusion which can be deduced from them is that specific conditions are required for induction of regenerants, their propagation, rooting and adaptation to field cultivation in each poplar species. However, we do not find data on obtaining regenerants and their propagation of Populus $\times$ berolinensis Dipp., a hybrid which appeared spontaneously in botanical garden of Berlin due to pollination of the female P. laurifolia $\mathrm{Ldb}$. with pollen of the male $P$. nigra $\mathrm{L}$. var. italica [25]. It inherited frost resistance from P. laurifolia and pyramidal crown from $P$. nigra and is used in East Siberia instead of south pyramidal poplars.

The aims of our work were: 1) to elaborate a protocol for obtaining adventive regenerants of $P . \times$ berolinensis and their following propagation in isolated culture, 2) to choose from these regenerants somaclonal variants with different growth rate, 3) to examine if these differences are conserved during field cultivation.

\section{MATERIALS AND METHODS}

Induction of adventive regenerants and their maintenance in isolated culture werte performed as described [22] with slight modifications. Branches from 3-years' old plants of $P . \times$ berolinensis were excised at the end of March 2009 and cultivated in the laboratory until young shoots were appeared from the buds. These shoots with leaf lamina removed were washed briefly with $0.1 \%$ water solution of Tween-80 followed by washing with tap water for $30 \mathrm{~min}$ and used for sterilization with 1) 70\% ethanol $1 \mathrm{~min}, 2)$ washing with sterile water, 3) $1 \%$ $\mathrm{NaOCl}$ with 1 drop of Tween-20 per $100 \mathrm{ml} 15 \mathrm{~min}$, 4) washing with sterile water 3 times for 3 min. Leaf laminas were washed and sterilized separately. 5-mm long sections of petioles and stem internodes without apical and axillar buds and $5 \times 5 \mathrm{~mm}$ pieces of leaf laminas were excised.

Each explant was placed in plastic vial (30 ml volume, "Sarstedt", Germany) with $10 \mathrm{ml}$ of P1 medium (Table 1). This medium contained TDZ in addition to BA and NAA, what favours the induction of regenerant appearance in woody plants [26]. The vials with explants were cultivated in growing room at $23^{\circ} \mathrm{C}$ which was illuminated with fluorescent lamps 16 hours per day. After 2 - 3 subcultures lasting 25 - 30 days, emerged regenerants were transferred into baby food jars $(200 \mathrm{ml})$ with polypropylene caps ("Sigma-Aldrich") and $30 \mathrm{ml}$ of P3 medium (Table 1) for their elongation. Elongated to 2 - 3 $\mathrm{cm}$ plantlets were transferred into jars or tubes $25 \times 150$ $\mathrm{mm}$ with the medium (P4, Table 1) containing IBA and cultivated in darkness at $23^{\circ} \mathrm{C}$ for 4 days. After that, they were cultivated with illumination for 20 - 25 days. Subsequent maintenance and propagation of plantlets were performed by the following way: apical segments $2-3$ $\mathrm{cm}$ long were excised and rooted as described. Plantlets with removed apexes were continued to cultivate until new shoots emerged from axillary buds and increased to $2-3 \mathrm{~cm}$. Then, they were also excised, rooted and grown.

Table 1. Compositions of media for isolated culture of $P$. berolinensis.

\begin{tabular}{|c|c|c|c|c|}
\hline \multirow{2}{*}{ Components, mg/dm ${ }^{3}$} & Induction of regeneration & Propagation of regenerants & Elongation & Rooting and propagation \\
\hline & P1 & P2 & P3 & P4 \\
\hline Macrosalts & $\frac{1}{2} \mathrm{MS}$ & $\frac{1}{2} \mathrm{MS}$ & $\frac{1}{2} \mathrm{MS}$ & $\frac{1}{2} \mathrm{MS}$ \\
\hline Microelements & MS & MS & MS & MS \\
\hline Saccharose & 20,000 & 20,000 & 20,000 & 20,000 \\
\hline Thiamine-HCl & 1 & 1 & 1 & 1 \\
\hline Pyridoxine-HCl & 0.5 & 0.5 & 0.5 & 0.5 \\
\hline Nicotinic acid & 0.5 & 0.5 & - & - \\
\hline BA & 0.2 & 0.5 & - & - \\
\hline TDZ & 0.02 & - & - & - \\
\hline Kinetin & - & - & 0.1 & 0.1 \\
\hline NAA & 0.01 & - & - & - \\
\hline IBA & - & 0.1 & - & 0.25 \\
\hline DEDTC & 5 & 5 & 5 & 5 \\
\hline Agar & 7000 & 7000 & 7000 & 7000 \\
\hline $\mathrm{pH}$ & 5.7 & 5.7 & 5.7 & 5.7 \\
\hline
\end{tabular}


Rooted plantlets were transferred from jars into plastic containers (volume $0.4 \mathrm{l}$ ) with marketed soil mixture of peat, vermiculite and mineral fertilizers in order to obtain transplants suitable for field cultivation. The containers were maintained in greenhouse with natural light and $20^{\circ} \mathrm{C}-25^{\circ} \mathrm{C}$ at days and $15^{\circ} \mathrm{C}-18^{\circ} \mathrm{C}$ at nights from the beginning of April to the end of May. They were defended from excessive transpiration with transparent plastic film for the first 10 - 12 days of cultivation. The transplants 25 - $30 \mathrm{~cm}$ long were planted into open field conditions on the experimental plot of the institute with $100 \times 60 \mathrm{~cm}$ between them. Two fertilizations with NPK were performed 2 and 4 weeks after planting. Weed removing and soil treatments were performed several times during cultivation. The heights of plants and stem diameters at $30 \mathrm{~cm}$ above the ground were measured at the end of September, when apical buds became dormant.

Cuttings $20-22 \mathrm{~cm}$ long from 1-year's field plants were excised in the next year at the end of March and indebted into haydite (5 - $10 \mathrm{~mm})$ of hydroponics' construction with 1 - 2 buds above the surface and irrigated daily with water solution of mineral fertilizers. After 12 14 days when roots appeared, they were transferred into plastic containers and transformed to transplants as described above. Field cultivation was performed as described above.

MS5524 basal salt mixture, agar, vitamins and plant growth regulators were purchased from "Sigma-Aldrich" and other components from "Helicon" (MGU, Moscow, Russia). Statistical errors were estimated with the use of Microsoft Excel Program by formula:

$$
S E=\sqrt{\frac{\sum(x-X)^{2}}{n(n-1)}}
$$

where $S E$ is standard error, $x$ is measurement, $X$ is arithmetic mean of $n$ measurements. Arithmetic means and their standard errors are indicated in Tables.

\section{RESULTS}

Conglomerates of calli and regenerants appeared on the explants after subculture on P1 medium (Figure 1). Some regenerates had greater dimensions of stems and leaves than others. Most of them had heights of $5-7 \mathrm{~mm}$ and were not suitable for rooting. In order to induce elongation, the conglomerates were cultured on the P3 medium (Table 1). The regenerants elongated to 15 - 20 $\mathrm{mm}$ after 1 month. They were separated from conglomerates and transferred on medium $\mathrm{P} 4$ for root induction. They were cultured 4 days in darkness and returned to light after that. Roots appeared after 10 - 12 days (Figure 2) and plantlets elongated after 25 - 30 days of cultivation. Significant differences in plantlet dimensions were observed at this stage (Figure 3). Following rooting and

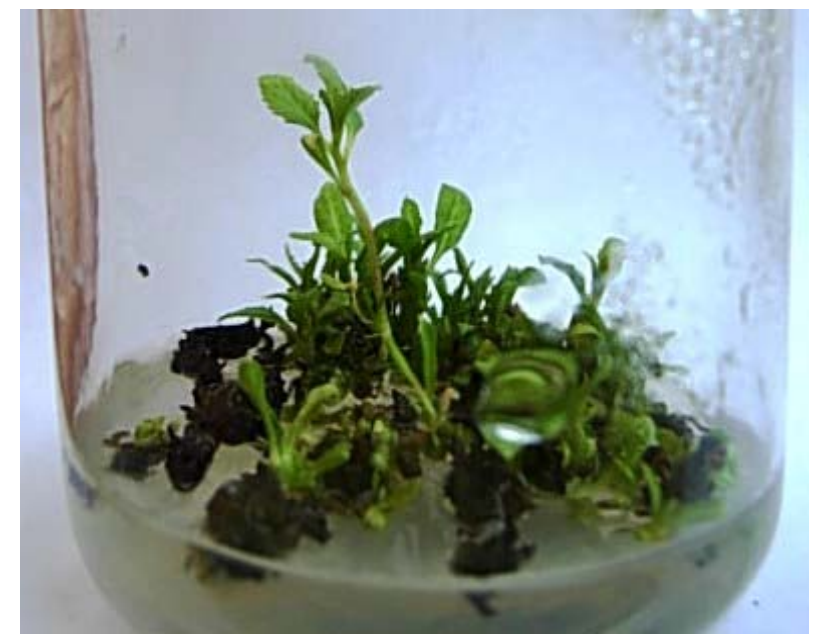

Figure 1. Adventive in vitro regenerants of Populus x berolinensis Dipp. appeared after transfer of conglomerates on elongation (P2) medium. The regenerant with greatest height is seen. Diameter of jar $-6 \mathrm{~cm}$.

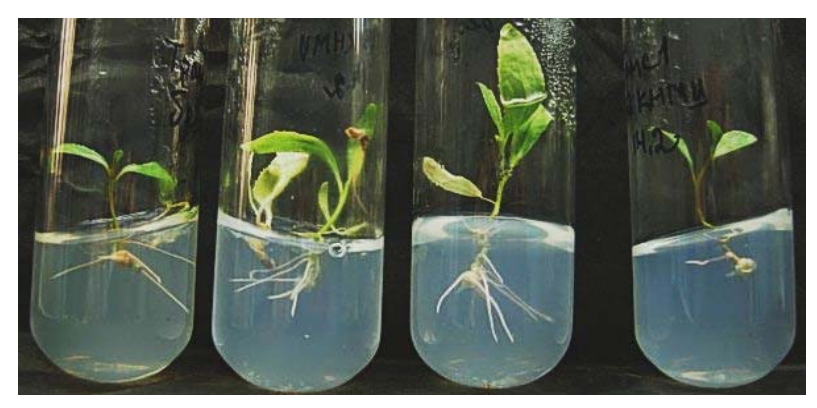

Figure 2. Rooted in vitro regenerants of Populus $\times$ berolinensis Dipp. Diameter of tubes $25 \mathrm{~mm}$.

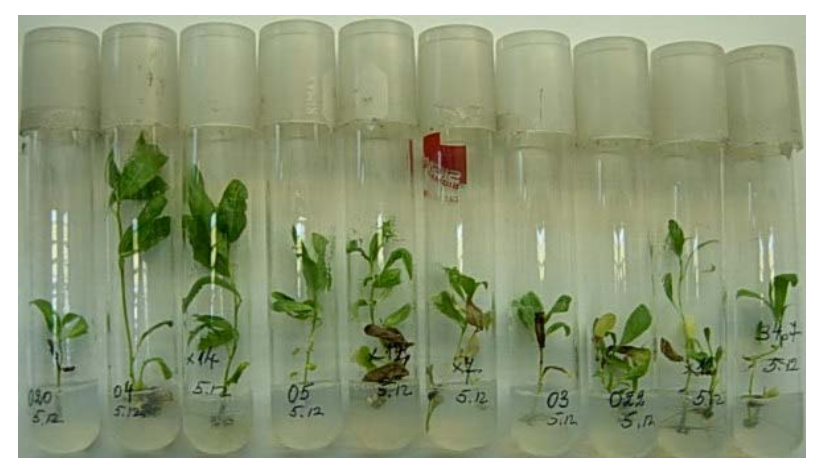

Figure 3. Differences between initial regenerants in plantlets dimensions. Diameter of tubes $25 \mathrm{~mm}$.

propagation of each initial regenerant were performed in separate baby food jars (Figure 4). Auxins stimulated root formation and shoot elongation, especially at the presence of $0.25 \mathrm{mg} / \mathrm{dm}^{3}$ IBA (Table 2). IAA was less active in these effects. Callus appeared on the base of stems inserted into the media with auxins and roots were produced from this callus. It was no callus formation before rooting in the absence of auxins. IBA 0.25 
$\mathrm{mg} / \mathrm{dm}^{3}$ was used for plantlet cultivation in vitro.

In order to produce clones from individual initial plantlets without further somaclonal deviations, their tops 2 - $3 \mathrm{~cm}$ long were excised and exposed to the rooting procedure, as described above and grew to new plantlets after 20 - 25 days. Cuttings excised below the apex failed to root and axillar buds of them did not evocated. The rests of the initial plantlets with apex removed were continued to cultivate until new shoots grew 15 - 20 $\mathrm{mm}$ long from the remaining axillary buds. These shoots were excised, rooted and also gave new plantlets. The removing of axillary shoots was possible to repeat 3 and more times from the same plantlet (Figure 5). By this way, 8 plantlets was possible to produce from initial plantlet after 3 such cycles of excision and 25 - 30 day's cultivations of apical and axillary cuttings. So, more than 50 clones were established to the spring of 2010.

Rooted in vitro plantlets were transferred to pots with soil and grown to obtain transplants for open field cultivation, as described in Materials and Methods (Figure 6). Differences of transplant dimensions were observed during the growth in greenhouse (Figure 7). More than 200 transplants were planted into field plot at the end of May 2010 and vegetated until the end of September (Figure 8). The results of measurements of stem length and thickness of 7 clones with smallest dimensions and 7 clones with greatest dimension are presented in Table 3. It may be seen that difference between means of these groups of clones exceeded $20 \%$. The greatest stem length was 210 $\mathrm{cm}$ and smallest one was $123 \mathrm{~cm}$.

In order to decide which parameter determines stem length differences: length of internodes or number of them, numbers of buds on $40 \mathrm{~cm}$ at the middle of stems was calculated. As shown in Table 4, approximately the same numbers of buds were observed in clones with small stem lengths and clones with great ones. By division of $40 \mathrm{~cm}$ of stem length on the number of buds, we obtained that mean lengths of internodes did not differ significantly between clones. So, it may be supposed that fast growing plants produce internodes with greater rate, than slow growing ones, whereas elongation of internodes proceeds with the same rate in both of them.

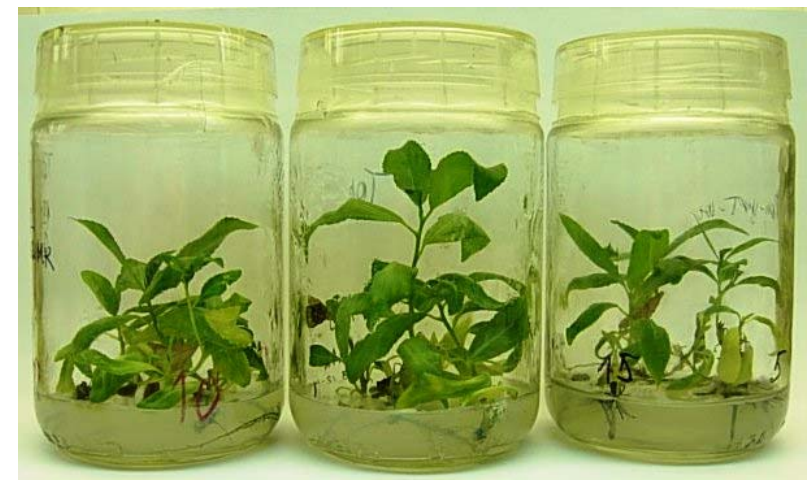

Figure 4. Micropropagation of individual clones from initial regenerants in baby food jars. Diameter of jar $-6 \mathrm{~cm}$.

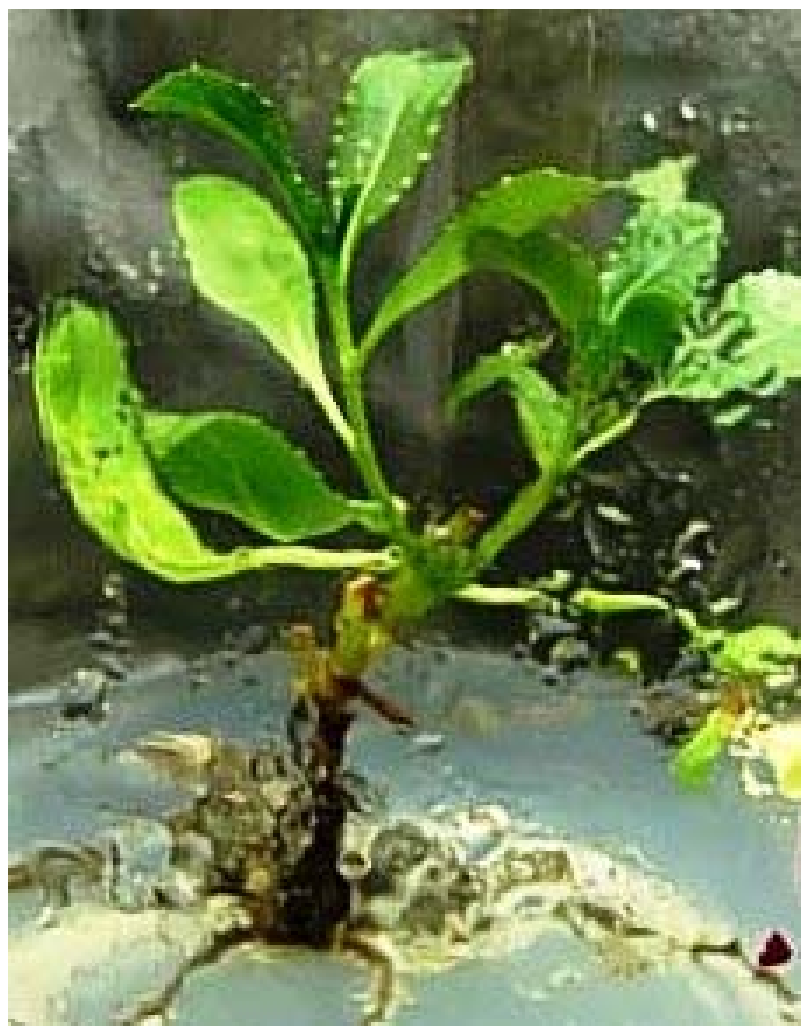

Figure 5. Plantlet of Populus $\times$ berolinensis Dipp. with two axillary shoots appeared 26 days after the excision of apical segment of the stem. The width of photo is $3.7 \mathrm{~cm}$.

Table 2. The effect of IBA and IAA on rooting and height of plantlets of $P$. $\times$ berolinensis after one month of in vitro culture.

\begin{tabular}{ccccc}
\hline Auxins, $\mathrm{mg} / \mathrm{dm}^{3}$ & $\begin{array}{c}\text { Per cent of plants } \\
\text { with roots }\end{array}$ & $\begin{array}{c}\text { Root number per } \\
\text { one plant }\end{array}$ & $\begin{array}{c}\text { Per cent of plants with callus } \\
\text { on the stem base }\end{array}$ & Height of plantlets, cm \\
\hline $0^{*}$ & $55 \pm 11$ & $0.78 \pm 0.32$ & 0 & $2.72 \pm 0.17$ \\
IBA 0.10 & $89 \pm 11$ & $1.56 \pm 0.38$ & $55 \pm 18$ & $3.39 \pm 0.37$ \\
0.25 & $\mathbf{1 0 0} \pm \mathbf{0}$ & $\mathbf{2 . 5 0} \pm \mathbf{0 . 4 5}$ & $\mathbf{1 0 0} \pm \mathbf{0}$ & $\mathbf{4 . 3 0} \pm \mathbf{0 . 2 9}$ \\
0.10 & $96 \pm 4$ & $1.44 \pm 0.38$ & $100 \pm 0$ & $3.00 \pm 0.17$ \\
IAA 0,25 & $78 \pm 11$ & $2.22 \pm 0.66$ & $78 \pm 15$ & $3.17 \pm 0.25$ \\
0.50 & $100 \pm 0$ & $1.70 \pm 0.40$ & $100 \pm 0$ & $3.35 \pm 0.32$ \\
\hline
\end{tabular}

"Arithmetic means and statistical errors, $\mathrm{n}=5$. 


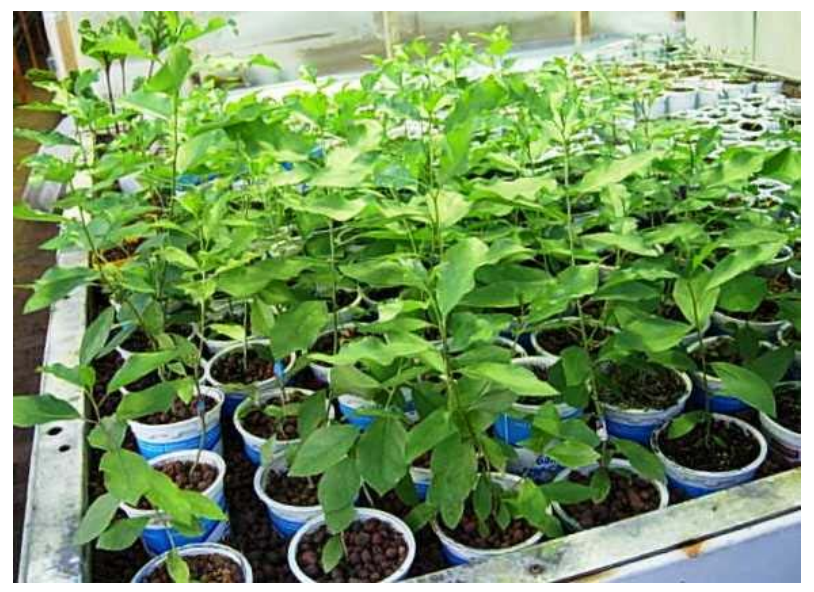

Figure 6. Transplants of Populus $\times$ berolinensis Dipp. grown from in vitro plantlets. Flask diameters $95 \mathrm{~mm}$.

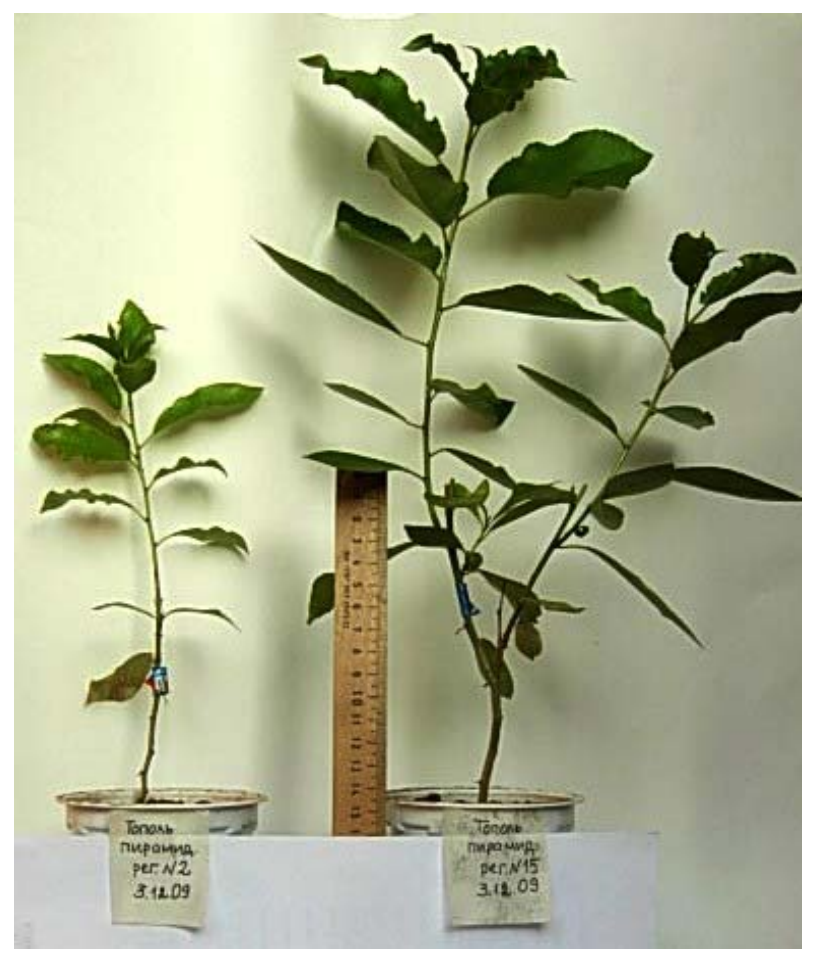

Figure 7. Different dimensions of transplants of Populus $\times$ berolinensis Dipp. during cultivation in greenhouse. Flask diameters $95 \mathrm{~mm}$.

A question arises, if differences in growth rate between clones will be reproduced in the next seasons at vegetative propagation of them. Stems with greatest and smallest lengths were excised at the onset of March 2011 and stored in cellar at $2^{\circ} \mathrm{C}-4^{\circ} \mathrm{C}$ until April. Then, 5 cuttings near to $20 \mathrm{~cm}$ long were excised and used for transplant production as described in Material and Methods. Rooted cuttings were transferred into pots with soil and cultivated to the end of May. Following planting to field and growing were accomplished as described in

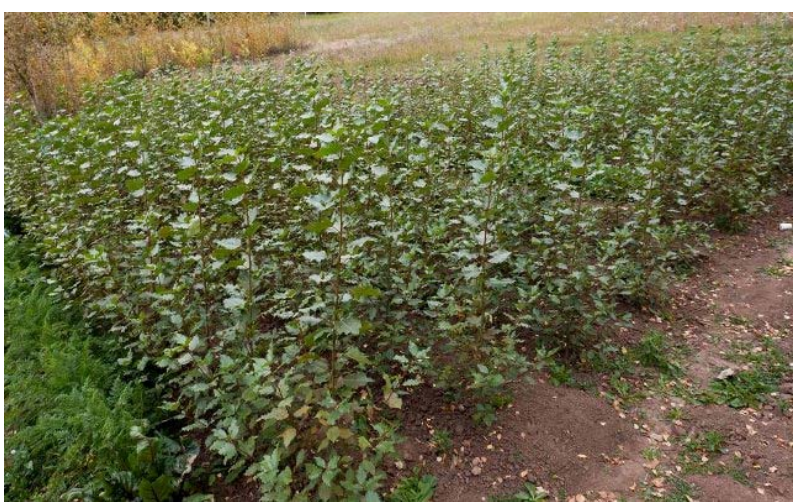

Figure 8. Field plants of Populus $\times$ berolinensis Dipp. grown from in vitro regenerants at 2010.

Material and Methods. The data of measurement of plants at the end of September are presented in Table 5. It may be seen that plants grown from cuttings excised from highest and smallest plants retained the abilities of mother plants to grow with different rates. So, it may be supposed that differences between regenerants raised due to somaclonal variability can be conserved through the vegetative propagation of them.

\section{DISCUSSION}

The aim of some works on genetic transformation of poplars is to fasten growth in height and thickness. For this purpose, a gene of GA 20-oxidase of Arabidopsis under control of CMV 35S promoter was included into aspen genome [6]. An increase of stem length of $10 \%$ $20 \%$ was also obtained by incorporation into aspen genome of cellulase gene of Arabidopsis [7] and rol-gene of Agrobacterium rhizogenes [27]. Stem diameter of aspen was also increased due to an increase of GA syntheses [28]. As shown in Table 3 of our work, the same or even more differences of stem height and diameter were observed between somaclonal variants of adventive regenerants. Different growth rates of regenerants from protoplasts of poplar were also described in work of Serres et al. [29]. It may be concluded that fast-growing woody plants may be obtained due to somaclonal variability.

It is interesting that the increase of stem length in our work was achieved due to greater number of internodes, whereas the increase as a result of increased GA1 and GA4 synthesis [6] or cellulase activity [7] in transgenic aspen was conditioned by an increase of internodes' length. Overexpression of pine glutamine synthetase in transgenic hybrid poplar caused an increase of number of internodes and leaf area [30]. Another example of stem growth regulation by the change of the rate of internodes' production was presented in the work of Tuominen et al. [31]: increased IAA content in hybrid aspen due to the 
Table 3. Stem length and diameter of field plants of $P$. $\times$ berolinensis, grown at 2010 from regenerants obtained in vitro (Means of 3 plants of each clone and their statistical errors are indicated).

\begin{tabular}{cccc}
\hline Clone types & Clone numbers & Stem length, cm & Stem diameter, mm \\
\hline Clones with smallest stem lengths & $12^{*}$ & $154 \pm 7$ & $13.7 \pm 1.6$ \\
& 16 & $159 \pm 7.6 \pm 1.5$ & $12.7 \pm 1.2$ \\
& 24 & $149 \pm 2$ & $11.5 \pm 2.5$ \\
& 26 & $150 \pm 23$ & $12.4 \pm 1.2$ \\
& 36 & $155 \pm 26$ & $12.4 \pm 2.5$ \\
& 41 & $140 \pm 18$ & $12.1 \pm 0.9$ \\
Mean of all clones & 21 & $157 \pm 2$ & $12.1 \pm \mathbf{1 . 7}$ \\
& 29 & $152 \pm \mathbf{8}$ & $13.5 \pm 2.9$ \\
& 21 & $181 \pm 7$ & $16.9 \pm 1.1$ \\
& 31 & $188 \pm 19$ & $16.5 \pm 1.3$ \\
& 33 & $190 \pm 28$ & $15.0 \pm 2.6$
\end{tabular}

*Arithmetic means and statistical errors.

Table 4. Morphometric parameters of field plants of $P$. $\times$ berolinensis, grown at 2010 from regenerants obtained in vitro. The highest plants of clones with greatest stem lengths and lowest plants of clones with smallest stem lengths were used for estimation.

\begin{tabular}{|c|c|c|c|c|}
\hline Clone number & Stem length, cm & Stem diameter, mm & Number of buds on $40 \mathrm{~cm}$ of stem length & Length of inter-node ( $40 \mathrm{~cm}$ number of buds) \\
\hline \multicolumn{5}{|c|}{ Highest plants } \\
\hline $4^{*}$ & 195 & 18.4 & 9 & 4.44 \\
\hline 31 & 199 & 18.5 & 11 & 3.64 \\
\hline 31 & 198 & 17.2 & 11 & 3.64 \\
\hline 33 & 210 & 20.2 & 10 & 4.00 \\
\hline 37 & 201 & 18.3 & 11 & 3.64 \\
\hline 40 & 207 & 18.4 & 9 & 4.44 \\
\hline 46 & 210 & 18.1 & 9 & 4.44 \\
\hline 54 & 209 & 17.0 & 10 & 4.00 \\
\hline Mean & $204 \pm 6$ & $18.3 \pm 1.0$ & $10.0 \pm 0.9$ & $3.97 \pm 0.36$ \\
\hline \multicolumn{5}{|c|}{ Lowest plants } \\
\hline 16 & 145 & 10.5 & 10 & 4.00 \\
\hline 24 & 147 & 12.0 & 12 & 3.33 \\
\hline 24 & 152 & 13.8 & 12 & 3.33 \\
\hline 38 & 152 & 13.2 & 10 & 4.00 \\
\hline 51 & 159 & 11.2 & 10 & 4.00 \\
\hline Mean & $151 \pm 5$ & $12.1 \pm 1.4$ & $10.8 \pm 1.1$ & $3.73 \pm 0.37$ \\
\hline
\end{tabular}

*Arithmetic means and statistical errors. 
Table 5. Morphometric parameters of field plants of $P . \times$ berolinensis, grown at 2011 from cuttings excised from plants of clones with smallest (sm) and hightest (hg) stem lengths.

\begin{tabular}{|c|c|c|c|c|}
\hline Clone number & $\begin{array}{l}\text { Total length of main stem } \\
\text { and lateral branches, cm on } 1 \text { plant }\end{array}$ & $\begin{array}{c}\text { Number of lateral } \\
\text { branches on } 1 \text { plant }\end{array}$ & $\begin{array}{l}\text { Length of main } \\
\text { stem, cm }\end{array}$ & $\begin{array}{c}\text { Mean length of lateral } \\
\text { branches, } \mathrm{cm}\end{array}$ \\
\hline $12 \mathrm{sm}$ & $118 \pm 42^{*}$ & 0.6 & $78 \pm 15$ & $34 \pm 15$ \\
\hline $16 \mathrm{sm}$ & $164 \pm 43$ & 1 & $77 \pm 20$ & $40 \pm 12$ \\
\hline $24 \mathrm{sm}$ & $114 \pm 24$ & 0.4 & $66 \pm 9$ & $34 \pm 7$ \\
\hline $24 \mathrm{sm}$ & $189 \pm 30$ & 2 & $92 \pm 10$ & $49 \pm 5$ \\
\hline $26 \mathrm{sm}$ & $159 \pm 21$ & 1 & $95 \pm 7$ & $64 \pm 13$ \\
\hline $51 \mathrm{sm}$ & $157 \pm 22$ & 1.4 & $100 \pm 14$ & $36 \pm 7$ \\
\hline Mean & $147 \pm 13$ & $1.07 \pm 0.23$ & $85 \pm 5$ & $50 \pm 3$ \\
\hline 4hg & $278 \pm 25$ & 2 & $123 \pm 6$ & $69 \pm 6$ \\
\hline 31hg & $262 \pm 34$ & 1.5 & $104 \pm 16$ & $58 \pm 5$ \\
\hline 31hg & $275 \pm 43$ & 2.2 & $119 \pm 12$ & $74 \pm 9$ \\
\hline 33hg & $261 \pm 34$ & 1.5 & $103 \pm 16$ & $57 \pm 5$ \\
\hline 37hg & $248 \pm 40$ & 1.5 & $115 \pm 15$ & $66 \pm 15$ \\
\hline 40hg & $201 \pm 38$ & 1.4 & $105 \pm 11$ & $64 \pm 13$ \\
\hline 46hg & $247 \pm 16$ & 2 & $127 \pm 10$ & $86 \pm 9$ \\
\hline 54hg & $199 \pm 45$ & 2 & $116 \pm 14$ & $57 \pm 11$ \\
\hline Mean & $239 \pm 13$ & $1.86 \pm 0.12$ & $114 \pm 3$ & $68 \pm 3$ \\
\hline
\end{tabular}

*Arithmetic means and statistical errors, $\mathrm{n}=5$.

inclusion of IAA-synthesizing genes from Agrobacterium tumefaciens led to the slower rate of internodes' production, whereas did not change internode's length. So, different mechanisms of stem growth regulation may exist, one-by the change of internodes' length and other -by the change of internodes' number. Genetic determination of the rate of internodes' production needs to be investigated.

Regenerants appeared in our work were adventive, i.e. originated from non-meristematic cells and some of them may be deviated from mother plant. To protect descendants of each initial regenerant from further changes during in vitro propagation, we applied a method in which apical parts of plantlets where excised, rooted and grew to the new plantlets. The remaining plantlets with removed apical parts were allowed to produce new shoots from lateral buds which were then excised also and applied for production of plantlets. Thus, new plantlets were produced from apical and lateral stem meristems. This way of propagation may diminish the probability of the appearance of new somaclonal deviations [32] after initial induction of adventive regenererants. It may be proposed that plants with increased growth rate can be possible to obtain by somaclonal variability and they may be used for practical purposes without restrictions existing for transgenic plants.
This work received partial financial support from Program of the Presidium of Russian Academy of Sciences "Chemical aspects of energetics", (project "Creation of transgenic plants for biofuel production”).

\section{REFERENCES}

[1] Murashige, T. and Skoog, F. (1962) A revised medium for rapid growth and bioassays with tobacco tissue cultures. Physiological Plant, 15, 473-497. doi:10.1111/j.1399-3054.1962.tb08052.x

[2] De Block, M. (1990) Factors influencing the tissue culture and the Agrobacterium tumefaciens-mediated transformation of hybrid aspen and poplar clones. Plant Physiology, 93, 1110-1116. doi:10.1104/pp.93.3.1110

[3] Bajaj, Y.P.S. (1986) Biotechnology of tree improvement for rapid propagation and biomass energy production. In: Bajaj, Y.P.S., Ed., Biotechnology in Agriculture and Forestry 1. Trees, Springer Verlag, Berlin, Heidelberg, 1-23.

[4] Ragauskas, A.J., Williams, C.K., Davison, B.H, Britovsek, G., Cairney, J., et al. (2006) The path forward for biofuels and biomaterials. Science, 311, 484-489. doi:10.1126/science.1114736

[5] Simmons, B.A. (2012) Bioenergy from plants and plant residues. doi:10.1016/B978-0-12-381466-1.00031-6

[6] Eriksson, M.E., Israelsson, M., Olsson O. and Moritz, T. (2000) Increased gibberellin biosynthesis in transgenic 
trees promotes growth, biomass production and xylem fiber length. Nature Biotechnology, 18, 784-788. doi:10.1038/77355

[7] Shani, Z., Dekel, M., Tsabary, G., Goren, R. and Shoseyov, O. (2004) Growth enhancement of transgenic poplar plants by overexpression of Arabidopsis thaliana endo1,4- $\beta$-glucanase (cel1). Molecular Breeding, 14, 321-330. doi:10.1023/B:MOLB.0000049213.15952.8a

[8] Boudet, A.M., Goffner, D., Marque, C., Teulieres, C. and Grima-Pettenati, J. (1998) Genetic manipulation of lignin profiles: A realistic challenge towards the qualitative improvement of plant biomass. Ag Biotech News and Information, 10, 295N-304N.

[9] Hu, W.J., Harding, S.A., Lung, J., Popko, J.L., Ralph, J., Stokke, D.D., Tsai, C.J. and Chiang, V.L. (1999) Repression of lignin biosynthesis promotes cellulose accumulation and growth in transgenic trees. Nature Biotechnology, 17, 808-812. doi: $10.1038 / 11758$

[10] Pilate, G., Guiney, E., Holt, K., Petit-Conil, M., Lapierre, C., et al. (2002) Field and pulping performance of transgenic trees with altered lignification. Nature Biotechnology, 20, 607-612. doi:10.1038/nbt0602-607

[11] Sepanen, S.K., Syrjala, L., Weissenberg, K.V., Teeri, T.H., Paajanen, I. and Pappinen, A. (2004) Antifungal activity of stilbenes and in vitro bioassays and in transgenic Populus expressing a gene encoding pinosylvin synthase. Plant Cell Reports, 22, 584-593. doi:10.1007/s00299-003-0728-0

[12] Jansson, S. and Douglas C.J. (2007) Populus: A model system for plant biology. Annual Review of Plant Biology, 58, 435-458. doi:10.1146/annurev.arplant.58.032806.103956

[13] http://genome.jgi-psf.org/ Poptr1/Poptr1.home.html

[14] Bradshaw, H.D., Ceulemans, R., Davis, J. and Stettler, R. (2000) Emerging model system in plant biology: Poplar (Populus) as model forest tree. Journal of Plant Growth Regulation, 19, 306-313. doi:10.1007/s003440000030

[15] Mann, C.C. and Plummer M. L. (2002) Forest Biotech Edges out of the Lab. Science, 295, 1626-1629. doi:10.1126/science.295.5560.1626

[16] Larkin, P.J. and Scowcroft, W.R. (1981) Somaclonal variation-A novel source of variability from cell cultures for plant improvement. Theoretical and Applied Genetics, 60, 197-214. doi:10.1007/BF02342540

[17] Huang, Y., Karnovsky, D.F. and Nauer, C.G. (1993) Applications of biotechnology and molecular genetics to tree improvement. Journal of Arboricilture, 19, 84-98.

[18] Karp, A. (1995) Somaclonal variation as a tool for crop improvement. Euphytica, 85, 295-302. doi:10.1007/BF00023959

[19] Chalupa, V. (1974) Control of shoot formation and production of trees from poplar callus. Biologia Plantarum, 16, 316-320. doi:10.1007/BF02921246

[20] Cheema, O.S. (1989) Somatic embryogenesis and plant regeneration from cell suspension and tissue cultures of mature Himalayan poplar (Populus ciliata). Plant Cell Reports, 8, 124-127. doi:10.1007/BF00716855

[21] Coleman, G.D. and Ernst, S.G. (1989) In vitro shoot regeneration of Populus deltoids: Effect of cytokinin and genotype. Plant Cell Reports, 8, 459-462. doi:10.1007/BF00269048

[22] Douglas, G.C. (1985) Formation of adventitious buds in stem internodes of Populus hybrid TT32 cultured in vitro: Effects of sucrose, zeatin, IAA and ABA. Journal of Plant Physiology, 121, 225-231. doi:10.1016/S0176-1617(85)80056-0

[23] Noël, N., Leplé, J.C. and Pilate, G. (2002) Optimization of in vitro micropropagation and regeneration for Populus $\times$ interamericana and Populus $\times$ euramericana hybrids (P. deltoids, P. trichocarpa and P. nigra). Plant Cell Reports, 20, 1150-1155. doi:10.1007/s00299-002-0465-9

[24] Russell, J.A. and McCown, B.H. (1988) Recovery of plants from leaf protoplasts of hybrid-poplar and aspen clones. Plant Cell Reports, 7, 59-62. doi:10.1007/BF00272979

[25] Skvortsov, A.K. (2010) Systematic conspectus of genus Populus in East Europe, Nord and Middle Asia. Bulleten Glavnogo Botanicheskogo Sada, 196, 62-73.

[26] Huetteman, C.A. and Preece, J.E. (1993) Thidiazuron: A potent cytokinin for woody plant tissue culture. Plant Cell Tissue Organ Culture, 33, 105-119. doi:10.1007/BF01983223

[27] Tzfira, T., Vinocur, B., Altman, A. and Vainstein A. (1997) rol-Transgenic Populus tremula: Root development, rootborne bud regeneration and in vitro propagation efficiency. Trees-Structure and Function, 12, 464-471.

[28] Israelsson, M., Eriksson, M.E., Hertzberg, M., Aspeborg, H., Nilson, P. and Moritz, T. (2003) Changes in gene expression in the wood-forming tissue of transgenic hybrid aspen with increased secondary growth. Plant Molecular Biology, 52, 893-903. doi:10.1023/A:1025097410445

[29] Serres, R., Ostry, M., McCown, B. and Skilling, D. (1991) Somaclonal variation in Populus hybrids regenerated from protoplast culture. In: Ahuja, M.R., Ed., Woody Plant Biotechnology, Plenum Press. New York, 59-61. doi:10.1007/978-1-4684-7932-4_7

[30] Jing, Z.P., Gallardo, F., Pascual, M.B., Sampalo, R., Romero, J., Navarra de, A.T. and Canovas, F.M. (2004) Improved growth in a field trial of transgenic hybrid poplar overexpressing glutamine synthetase. New Phytology, 164, 137-145. doi:10.1111/j.1469-8137.2004.01173.x

[31] Tuominen, H., Sitbon, F., Jacobsson, C., Sandberg, G., Olsson O. and Sundberg, B. (1995) Altered growth and wood characteristics in transgenic hybrid aspen expressing the Agrobacterium tumefaciens T-DNA inoleaceticacid biosynthetic genes. Plant Physiology, 109, 11791189.

[32] Debergh, P.C. and Read, P.E. (1991) Micropropagation. In: Debergh, P.C. and Zimmerman, R.H., Eds., Micropropagation. Technology and Application, Kluwer Academic Publishers, Dordrecht, 1-14. 


\section{ABBREVIATIONS}

BA: $\mathrm{N}^{6}$-benzylaminopurin, CMV: cauliflower mosaic virus, DEDTC: Na-diethyldithiocarbamate, GA: gibber- ellic acid, IAA: 3-indoleacetic acid, IBA: 3-indole-3butyric acid, MS: Murashige and Skoog [1] medium, NAA: 1-naphthalene acetic acid, TDZ: thidiazuron. 